\title{
Where the wild zebrafish are
}

\author{
Journeying into the field to study a model organism in its natural habitats.
}

\author{
Ellen P. Neff
}

W

hen Anuradha Bhat started studying Danio rerio, it wasn't in India - the country from which both she and zebrafish hail - but rather, Indiana, over 8,000 miles away in the laboratory of Emilia Martins, then a researcher at Indiana University Bloomington.

Those zebrafish in Bloomington were among countless others in a growing number of research labs. Since George Streisinger's initial work to establish Danio rerio as a biomedical model system, which began in the 1960s at the University of Oregon $^{1}$, the zebrafish now features across a wide range of research areas, from evolution and developmental biology to toxicology and drug development to neuroscience and beyond.

Bhat, a fish ecologist rather than a biomedical researcher, is interested in behavior. During her postdoctoral work at St. Andrews in Scotland, she worked with the Trinidadian guppy, Poecilia reticulata, studying how different environmental conditions influenced behaviors, such as aggression and shoaling. Her move to Indiana offered her an opportunity: to return to India to study zebrafish in their natural habitats.

"That's when my interest in zebrafish evolved, and I decided this is what I wanted to do," Bhat says. "There were so many questions." Even though the zebrafish has been a model organism for decades and can now be found in over 1200 (and counting) laboratories around the world, relatively little is known about its natural history ${ }^{2}$. "I realized that our understanding of zebrafish has been limited to those populations that have been brought.... into the lab," says Bhat. Those lab fish have undergone generations of artificial selection (intentional and otherwise) and their habitats - polycarbonate or glass tanks - differ greatly from those that a zebrafish will experience in the wild. "If somebody has been working with the 'wild type' zebrafish from a typical zebrafish lab, they will be surprised to see how different they are from the real wild zebrafish," she says.

So for the past decade, now as a researcher at the Indian Institute of Science Education and Research in Kolkata, Bhat

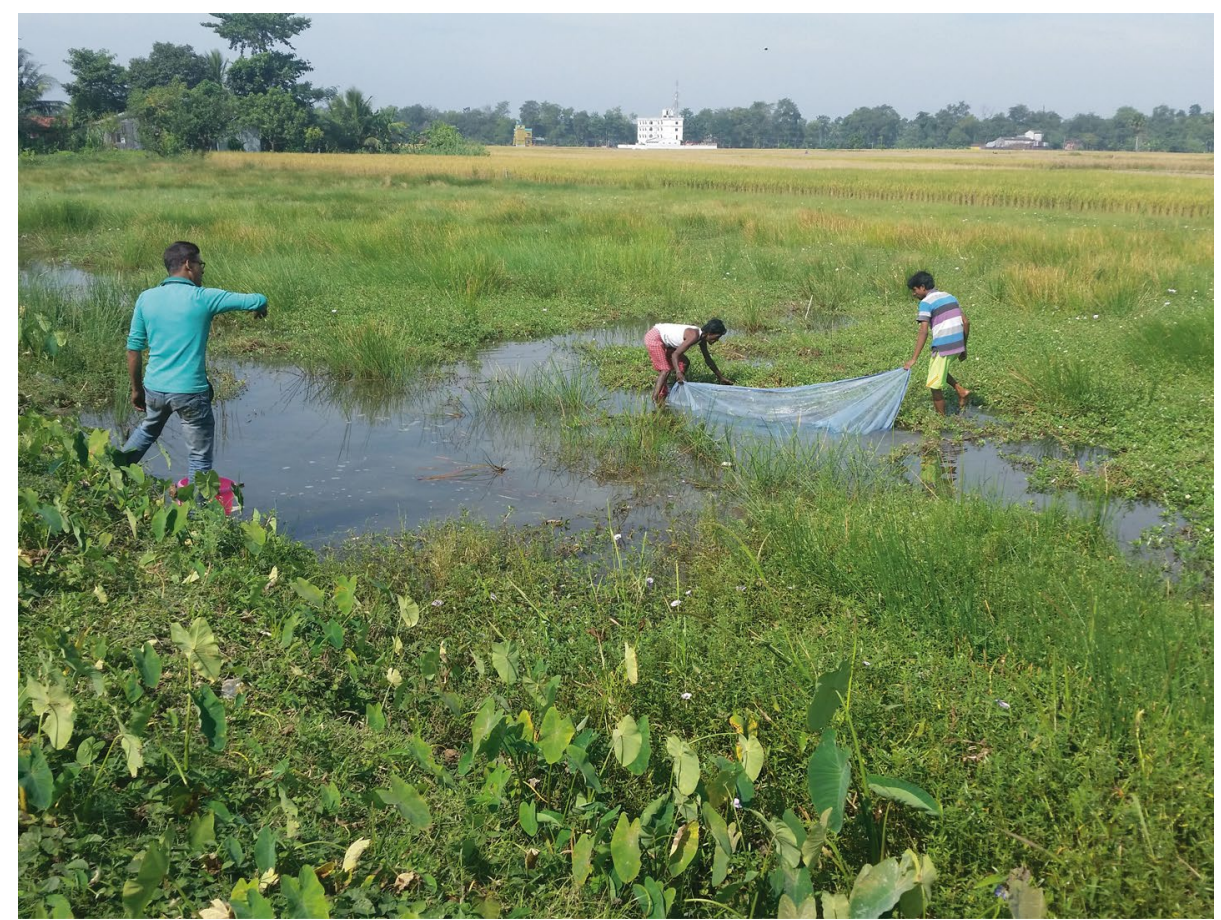

Nets out | Fisherman Bhattacharjee 'Bapi' Sukanta encourages Sagar and Raju as they deploy a seine net to capture zebrafish in shallow water in an open area of a rice paddy in West Bengal, India Credit: Delia Shelton. Credit: Delia Shelton

spends her days out in the field (as well as back in the lab) with wild zebrafish, one of a growing handful of researchers exploring the natural history of the popular model organism and the behavioral and genetic differences between those fish and their lab-bred brethren. Getting to the field to study them, however, comes with challenges that are likely to be a little unfamiliar to those who spend their time in fish facilities. It can, however, be worth the effort for those who undertake the journey.

"The 'wild-type' zebrafish are actually not that wild," Bhat says. "The wild ones are found in the natural habitats."

\section{Into the wild}

Those truly wild fish call the Indian subcontinent home. With a range naturally bounded to the north by the Himalayan Mountains and by seas to the south, zebrafish populations have been reported throughout peninsular India and Bangladesh, as well as in areas of Pakistan, Nepal, and Myanmar. There, populations can be found in a number of different environments, from flooded rice paddies and irrigation channels to streams, inlets, and the flood plains of large rivers, such as the Ganges and Brahmaputra. These diverse habitats have variable flows, substrates, and vegetation, and likely expose the fish to a variety of temperature ranges and water qualities that shift throughout the year as monsoon rains come and $\mathrm{go}^{3}$.

"I was amazed at the diversity of habitats we found them in," says Dave Parichy, a researcher at the University of Virginia who studies pigment biology and how those patterns influence behavior. After spending considerable time studying cellular interactions, questions about what this means for a wild zebrafish brought him to India over a decade ago ${ }^{4}$. 
There, morphological differences from laboratory fish weren't as drastic as he and his colleagues had hoped to find, but pigmentation did vary. "I've looked at pigmentation patterns for over two decades, and that made me stop and say, 'Hey, that's cool," he recalls. There is, for example, a particular pigment cell near the edges of the zebrafish's fins - seeing the fish in the wild highlighted how these cells would stand out in different environments. Those field observations provided context for functional studies years later that might not have been possible otherwise, says Parichy "It's more having a feel for the organism," he says.

The logistics behind such a trip were - and can remain - a challenge. While locally based researchers such as Bhat can find population within a few kilometers of her lab outside Kolkata, that's just a small sampling of where the fish can be found; excursions can take researchers much further afield. After spending over a day in transit from Oregon to Kolkata for a recent research trip, Delia Shelton recalls spending an additional 17 hours on a train to then get to Cooch Behar; after that, there were additional hours of driving to find the fish in the field. Shelton, a NSF predoctoral fellow on her first trip to India and a NSF postdoctoral fellow on her second, was interested in studying the hallmarks of collective zebrafish behavior - for example, when fish shoal together, are they being directed, or are they rather following simple 'traffic rules?'

For western researchers who don't speak Hindi (in any of its regional dialects) or other local languages, such trips require local contacts. Not just with scientific collaborators such as Bhat, who can help advise on field sites and conditions ahead of a trip - traveling during monsoon season, for example, is unlikely to be fruitful - but also with the drivers, who provide the transport the teams and their equipment rely on to venture into what can at times be vicarious terrain, and fishermen, who know when and where to look for the fish while being cognizant of any concerns and restrictions from the surrounding communities.

"We've relied a lot on local knowledge," says Shelton. "India is huge, and it's diverse." When manuscript reviewers question field sites, Shelton reminds them of the necessity involved: "Those are where our collaborators live, and those are the languages that they speak.... That's where we knew that we had a connection with the villagers, in that we weren't just taking from them but that we could partner with people there."

To study wild zebrafish, you first have to find them. Walk into a tank room and you

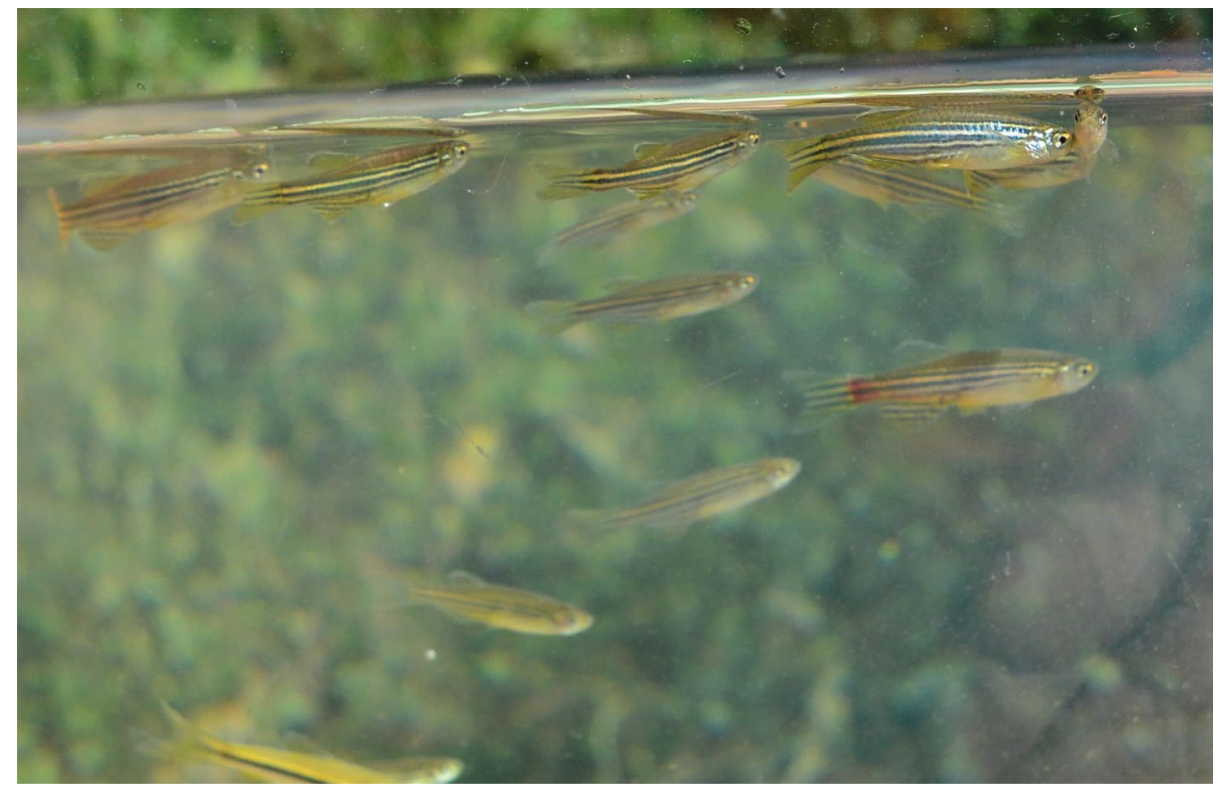

The wild things | Wild zebrafish captured using hand nets and fine mesh seines in Sidi Halla, Karnataka, Southwest India. Credit: Rafael A. Lara and Raquel O. Vasconcelos

can be reasonably certain your fish will be there waiting for you. In the field, that's no guarantee - a location may look suitable for a zebrafish to us, but the fish often disagree. "In certain areas you'll find them in huge numbers, but in some areas you expect them to be, they are not there," says Bhat, noting too the seasonal pattern to where they can be found. "We have had fantastic times when we could find our populations the way we want them," she says. "Then we've had completely fruitless excursions where we have gone [out] for days and not found anything, and come back feeling very sad and depressed."

When zebrafish are to be found, field teams can have long, hot, mosquito-filled days installing their cameras and behavioral testing arenas, recording the ambient conditions they are interested in, and, if appropriate permits have been obtained, capturing wild fish to bring back to the lab for further, somewhat more controlled, study. "In a lab, you can control for everything" says Bhat. Not so in the field. "It all depends on what the habitat is like," she says. What do you do if you can find zebrafish but can't see them beyond a few centimeters? Cameras and video equipment become moot if the water is too turbid or silty. "Then, we have to redesign our experiments and decide, 'Ok, this cannot be done in the water', so we might have to bring them out and transfer them to a smaller enclosure and do some simpler experiment," Bhat says.

Unexpected challenges extend beyond the fish themselves. Worried about water damage back at the bench? What about water buffalo damage? Thankfully, Shelton's cameras and other field equipment were spared the hooves of some local bovines making their way to the same watering hole she and her colleagues hoped to study, but the experience underscores the need to be prepared for unexpected interruptions. Another day, they did lose an experiment to interlopers: crabs, which proceeded to cut the lines holding zebrafish-sized pieces of fish for a predation experiment. That was an unexpected turn for the team, but not to the local fishermen accompanying them.

"The fishermen were like, 'Oh yeah, of course that would happen - you should have asked us," Shelton laughs. Another day, those fishermen helped Shelton and her colleague, Piyumika Suriyampola avoid a more serious situation, interceding on their behalf to prevent another group of fishers from electrofishing in the area the team was working. "We were lucky," says Shelton. "You really have to have this huge team, that aren't necessarily recognized by the science community as authors, right, but they're central for conducting this research."

\section{Findings afield}

Field trips can be taxing, but findings from them can reveal new details about the natural lives of zebrafish, which can in turn help inform how the animals are studied and cared for back in the lab. Studying wild populations can help provide insights into the selective forces that have shaped the evolution of specific traits in the fish, says 
Bhat, which might help explain inherent characteristics that are of interest to researchers using them as model organisms.

For example, zebrafish aren't known to be a loquacious species, but they do listen to what's going on around them; this has prompted their use as an animal model for hearing research. Given the genetic and molecular toolkits available, Raquel Vasconcelos from the Institute of Science and Environment at the University of St. Joseph in Macau recently made the switch from chatty Lusitanian toadfish to zebrafish in her research into auditory processing. But, with her lab preparing to study the effects of noise and aging on the zebrafish auditory system, Vasconcelos realized they were missing an important detail. "We actually don't know what they hear in wild," she says. "Even though they have been widely used in hearing research, no one has looked into the features of their natural soundscapes."

What if, she wondered, her results were being affected by stress from unnatural noise - from the pumps and filters continuously running in the background? "Are we going to be working with a phenotype that is... comparable to their natural phenotype, or is this something totally artificial?" she says.

So a few years ago, she and Rafael Lara, a $\mathrm{PhD}$ student in her lab, organized a field trip to characterize the acoustic environment at five representative zebrafish habitats in India ${ }^{5}$, "to get an idea of the variability in terms of the sound pressure levels and also the spectral features in those different habitats," she says. Some places were quiet, about 102 to $107 \mathrm{~dB}$ and punctuated only by the occasional sounds of birds or water insects, or cavitation as the water slowly moved. In other areas, the noise was near constant; the loudest area sampled was in the main stream of the Tunga River in Shringeri, with noise reaching $126 \mathrm{~dB}$; there was, however, a silent window there that occured within the hearing range of zebrafish, she notes.

The differences between habitats - variables including noise, predation pressures, water flow and quality, the diversity of vegetation, and the type and complexity of substrates present - can indeed influence zebrafish in ways that researchers are now working to tease apart. "From an ecological perspective, one would expect that in these different kinds of conditions, different populations would evolve different strategies to be able to survive and reproduce successfully," says Bhat. She and her collaborators hope their studies of wild zebrafish will help answer questions such as how populations survive when the challenges they face vary; when conditions do change, how flexible are behavioral responses; and to what extent is that genetically controlled?

Compared to the various laboratory lines of zebrafish, wild specimens can look and behave differently, notes Bhat. Physically, wild zebrafish are usually smaller and skinnier than your typical lab-bred fish, and

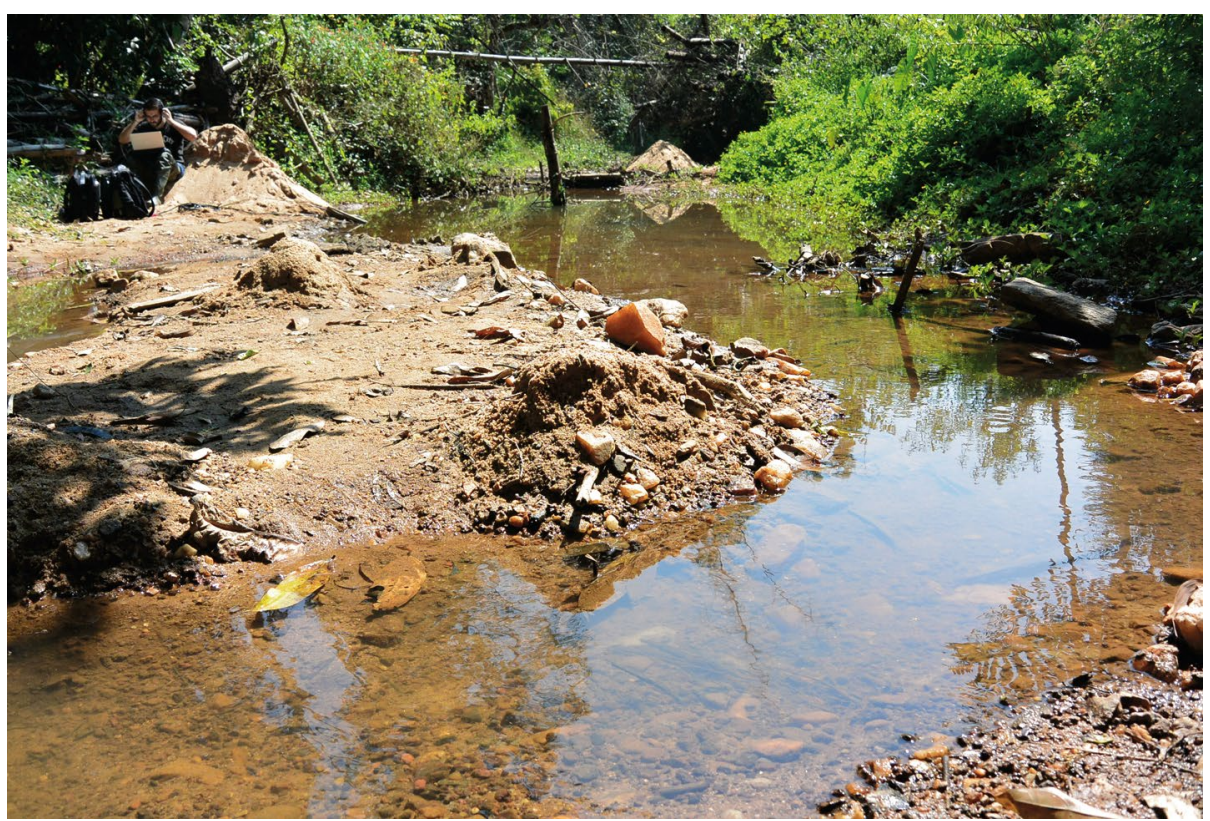

Field work | A shallow stream in Sidi Halla with sandy, lime, and silt substrate near Shivamogga (Karnataka). Here, zebrafish occurred in compact shoals of 5-10 individuals. Credit: Rafael A. Lara and Raquel O. Vasconcelos they can tend to be a bit shy. Put a hand up next to the tank, says Bhat, and fish collected from the wild will appear quite skittish, while the presence of people tends not to bother individuals from laboratory lines as much.

Appearance, personality traits such as boldness and aggression, and social dynamics such as group size and shoaling behavior can however vary considerably between different wild populations, influenced by the geographic location of the populations as well as the water flow and vegetation present ${ }^{6,7}$. In the field, some populations show polarized shoaling behavior - individuals orienting in the same direction - while others don't, notes Shelton. "We've been able to see diversity in these zebrafish in terms of their social behavior and also the habitats," says Shelton. In a lab-based study, she varied group size with water flow, revealing that these interact to affect polarized schooling, a hallmark of collective behavior.

Genetic differences abound as well. When Jaanus Suurväli joined Maria Leptin and Thomas Wiehe in studying zebrafish genetics for a postdoctoral position at the University of Cologne, he assumed the field knew everything there was to know about their model organism. "You have a very, very well controlled system, in which you know exactly what kind of fish you have," he recalls having thought, but that's not quite the case. "There's a ton of stuff that we don't know about an animal that has been studied for more than 50 years."

Though Suurväli hasn't yet made a trip to India himself, he joined up with collaborators who had; they provided wild fish sampled from India, Nepal, and Bangladesh for DNA comparison against samples of four commonly used laboratory lines. While those lab animals looked most similar to wild fish from India, Suurväli and his colleagues documented considerable variability, with the lab lines lacking nearly $60 \%$ of the genetic variations observed in

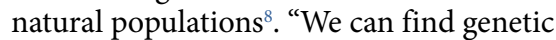
variants in the wild that we don't really know anything about yet," he says. "This is all a huge of amount of biological variation that has not been studied." The distinct genetics of the Nepalese and Bangladeshi fish in particular may merit further study; as in humans, Suurväli says, it can be difficult to make sweeping genetic conclusions based on individuals of similar origins.

Lab fish represent a small slice of the variation possible among zebrafish, notes Parichy. "In some ways we know, but in some ways we don't know, what we selected for," he says; this could be a limitation in interpreting some results, but also provides 


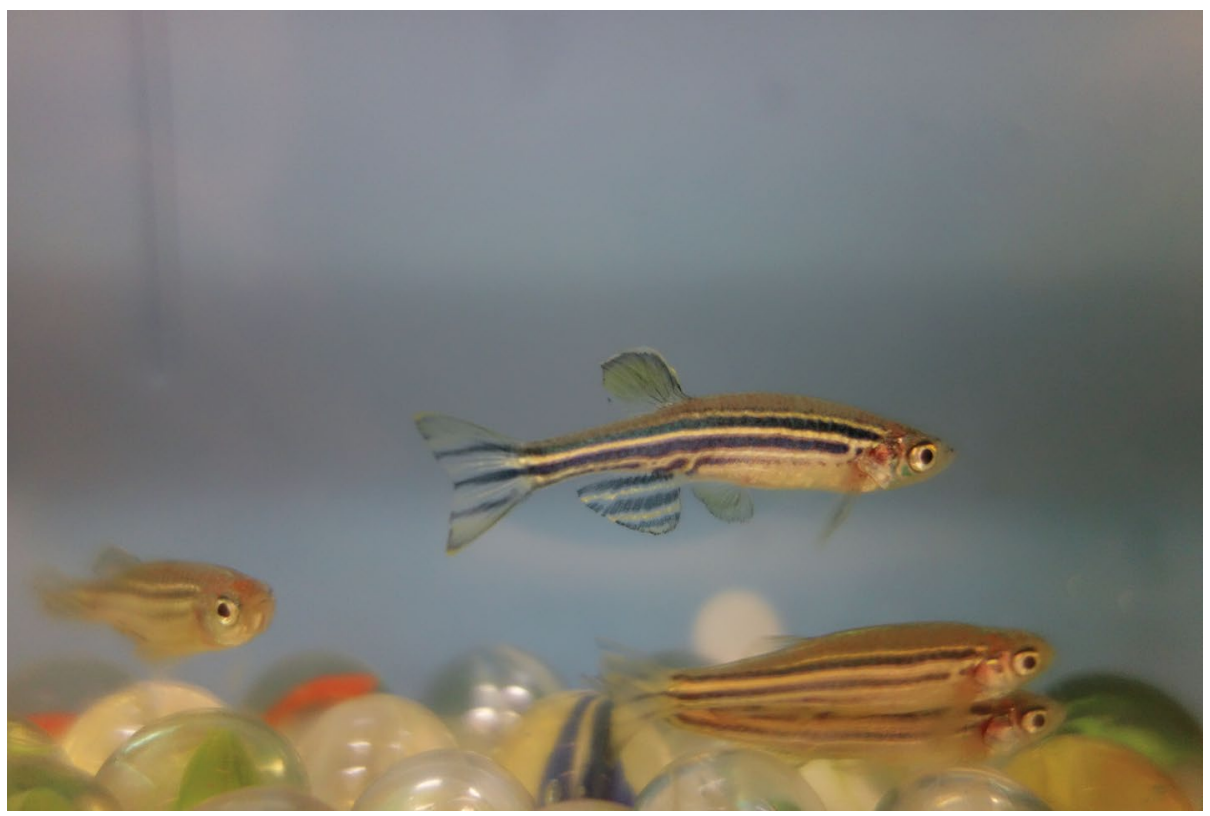

Added complexity I In the wild, zebrafish spawn over gravel; in the lab, fish get marbles. Credit: Delia Shelton

opportunities to study the genetic basis for trait evolution.

\section{Back to the lab}

How relevant the differences between wild and lab-bred zebrafish are may ultimately depend on the particular questions being asked. But, says Bhat, lab-based researchers should still be mindful of what studies with wild fish can reveal - particularly if they are interested in cognition and behavior. "Depending on what kind of local environment they are raised in, their cognitive abilities actually differ," she says. For example, fish captured from complex habitats may be bolder and better navigators than those inhabiting simpler environments ${ }^{9,10}$ likewise, Bhat's work has shown that juveniles collected from complex environments are better navigators than those raised in bare tanks ${ }^{11}$. It's an area she and her lab continue to explore, but she suggests the effects of habitat on cognition likely relate to the extra challenges the fish must overcome in finding resources, such as food and mates, in the field.

For Shelton, observations of wild fish have informed how she studies behavior back in the lab. "There's this idea that, well, fish do move in three dimensions," she says. "Do we need to have all of those dimensions to get an accurate picture of their behavior?" Yes and no - while they do indeed move in three dimensions when the water is deep enough, zebrafish also inhabit shallow waters, where it becomes hard for them to swim up and down? . "Two-dimensional analysis ... does accurately allow us to capture their behavior," she says.

Outside of experimental research, the daily lives of lab fish might also benefit from better understanding of their wild relatives. "If we investigate the ecology of zebrafish, I think that would allow us to come up with primary research questions," says Carole Lee, a PhD student studying zebrafish welfare at Exeter University. "That could then help with husbandry." At the moment, Lee is looking at group size in laboratory tanks and its influence on behavior. "We can get a lot of aggression with zebrafish, especially with small groups," she says. It would be interesting to know more about group sizes in the wild, she says. For example, how much do they vary, and how stable are they

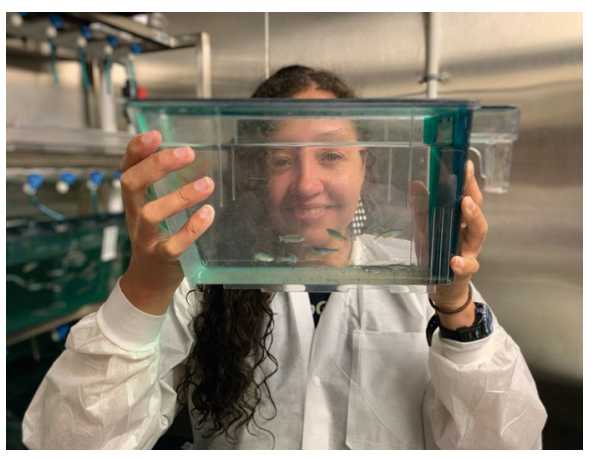

For the fish | Delia Shelton, with a tank of zebrafish. Credit: Tracy L. Meese over time? Does group size change while fish are foraging?

Beyond the social dynamics - sizes, sex distributions, ages, etc. - there are physical parameters to consider as well: $\mathrm{pH}$, nitrogenous compounds, salinity, dissolved oxygen, and so on. Given the diversity of habitats the fish can live in naturally, they can be quite tolerant of a range of different water qualities, says Lee; as such, differences from fish facility-to-fish facility may not affect the individual zebrafish housed there, but that variability may contribute to reproducibility issues in between.

Standards are being considered by groups as the Zebrafish Husbandry Association and its European counterpart, says Lee, as well as efforts to understand the best conditions for them. "The thing is, we need evidence of what's optimum," says Lee. "We need evidence-based research." That will come from laboratory work, as well as more investigations of the habitats and microhabitats the fish inhabit naturally. "It's one of those things that the more you learn, the more you realize that we don't know," Lee says. "The main thing for me is that better welfare leads to better science."

"Seeing them in the wild and seeing what kind of substrates they are on has really helped inform that for us, and we hope that helps inform other husbandry questions too," says Shelton. Sampling light conditions in the wild helped her and her colleagues identify light parameters that were low enough to retard excessive algal growth, minimizing the need for tank changes, without negatively impacting visual development.

In the field, the fish live in 'biologically rich' environments, notes Parichy. Whereas many might want their tanks to remain relatively sterile, the fish might in fact like a little of that algae and biofilm. "One of the things we learned was, leave the fish alone a little bit more," says Parichy. In his lab, they reduced tank changes and also reduced salinity levels from those recommended by the tank systems manufacturers. If the goal is fecund, healthy animals, it's important to minimize stress and give the fish a little of what they like, he suggests.

It can also be important to minimize what they don't like. With data on natural sound levels in the field, Vasconcelos also recorded acoustic properties in three different zebrafish housing systems. Those tanks could be loud, ranging up to $146 \mathrm{~dB}^{5}$. A follow-up study of laboratory fish revealed temporary hearing loss at 130-150 dB and damage to hair cells, which enable hearing, at $150 \mathrm{~dB}^{12}$. While the fish can regenerate those hair cells, thus restoring their hearing and providing a useful means to study the 
mechanisms of hearing loss and recovery in response to both aging effects and noise damage, the ambient noise in fish facilities could indeed be stressful to the fish and potentially confound other work.

In addition to using the zebrafish as a model, Vasconcelos is studying cortisol levels in adult fish exposed to different decibel levels and time regimes, as well as the impacts of noise on embryonic development. Although she hasn't made it back afield, she also thinks it would be interesting to sample the hearing sensitivities of the real wild types, to compare against any changes that have occurred over the course of laboratory selection; this might help researchers get a better sense of the mechanisms of phenotypic adaptation to captivity and acoustic stress, she says.

There are also opportunities for the lab fish to give back to their wild cousins, and the nearby human communities that rely on the same water ways. As zebrafish have long been used in toxicology research, Shelton (now a NIH National Institute of Environmental Health and Safety K99/ R00 Postdoctoral Fellow at Oregon State University) hopes use laboratory zebrafish to improve the environmental health and safety of the animals' home lands. When zebrafish occur in polluted waters, their behavior changes, Shelton notes - could that pollution, from heavy metals such as cadmium, be affecting the nearby humans as well? "It would be great to see how we can use these fish as sentinels for pollution," says Shelton, while taking advantage of the experimental toolkit available in the lab to better understand the mechanisms involved in any disease or other impairments that arise from pollutant exposure.

\section{Onward and outward}

Studies of the real wild types go on. "Doing fieldwork is quite different from doing lab work," says Bhat. "We have tried to do a combination of both, because there are pros and cons [to each]." But like other wild animals, wild zebrafish don't always take immediately to the lab environment. Many will die in transport, she says, and those that make it to the lab take time to acclimatize to their new, artificial conditions.

Breeding wild fish has been an unexpected challenge as well. "The literature says it's easy - it just gives you a couple steps," says Bhat. Males plus females...add substrate to the collect the eggs, and voila!: embryos. "We tried to do this with the wild fish, and we have been really, really finding it difficult." The fish tend to not be particularly interested in spawning, and fertilization of the eggs they do lay tends to be hit or miss, yielding too few juveniles for experiments.

She continues on with the attempts, and with field studies, accompanying both her own lab and a growing number of western-based researchers looking to observe the real wild things. "I definitely think it is worth it," says Shelton, who collaborated with Bhat on her trip. "It gives me a broader perspective."
Those working with wild fish have much to thank from the biomedical community as it teases apart the secrets of zebrafish genetics and development; Bhat hopes that field studies can return the favor. "I hope that what we are doing would be useful," she says. "Now they can understand the zebrafish system from a natural perspective as well."

Ellen P. Neff $\bowtie$
Lab Animal.
$\bigotimes_{e-\text {-mail: ellen.neff@us.nature.com }}$

Published online: 15 October 2020

https://doi.org/10.1038/s41684-020-00665-Z

References

1. Grunwald, D. J. \& Eisen, J. S. Nature Genet 3, 717-724 (2002).

2. Parichy, D.M. eLife (2015) https://doi.org/10.7554/eLife.05635.001

3. Lee, C.J., Tyler, C.R., Paull, G.C. Chapter 4 - Georgraphic Range and Natural Distribution in The Zebrafish in Biomedical Research. Cartner, S.C. et al. (eds) (2020) https://doi.org/10.1016/ B978-0-12-812431-4.00004-X

4. Engeszer, R. E., Patterson, L. B., Rao, A. A. \& Parichy, D. M. Zebrafish 4, 21-40, https://doi.org/10.1089/zeb.2006.9997 (2007).

5. Lara, R. A. \& Vasconcelos, R. O. Zebrafish 16, 152-164, https:// doi.org/10.1089/zeb.2018.1654 (2019).

6. Suriyampola, P. S. et al. Zebrafish 13, 1-8, https://doi.org/10.1089/ zeb.2015.1159 (2016)

7. Shelton, D. G. et al. Zebrafish 4, 243-252, https://doi.org/10.1089/ zeb.2019.1851 (2020).

8. Suurväli, J. et al. Mol Biol Evol 37, 1056-1069, https://doi. org $/ 10.1093 / \mathrm{molbev} / \mathrm{msz} 289$ (2020).

9. Roy, T., Shukla, R. \& Bhat, A. Zebrafish 14, 393-403, https://doi. org/10.1089/zeb.2017.1442 (2017).

10. Daniel, D.K., Bhat, A. Front Behav Neurosci (2020) https://doi. org/10.3389/fnbeh.2020.00138

11. Roy, T. \& Bhat, A. Ethology 122, 308-318, https://doi.org/10.1111/ eth.12470 (2016).

12. Breitzler, L., Lau, L. H., Fonseca, P. J. \& Vasconcelos, R. O. Hear Res 391, 107952, https://doi.org/10.1016/j.heares.2020.107952 (2020). 